\title{
Revisão do Simulium spinibranchium Lutz, 1910 (Diptera: Simuliidae), com a primeira descriçāo dos adultos e larva, e redescriçào da pupa
}

V. Py-Daniel (')

A. J. Shelley ${ }^{(2)}$

\section{Resumo}

Os adultos e larva de Simulium spinibranchium Lutz. 1910 são descritos pela primeira vez, como também é redescrita a pupa. E designado um lectótipo para a espécie. São apresentados a distribuição geográfica e alguns dados sobre a biologia.

\section{INTRODUÇÃO}

Lutz (1910) descreveu $q$ de Simulium subpallidum n.sp.

Associa-lhes pupas que, no entanto, no mesmo trabalho são apresentadas como espécie nova, S. spinibranchium, deixando em aberto uma possivel sinonímia.

Pinto (1931) descreve a pupa de subpallidum, que confirma spinibranchium como espécie válida.

Apresentamos neste trabalho a primeira diagnose dos adultos e larva, e redescrição da pupa, estabelecendo definitivamente, a identidade da espécie.

\section{Simulium spinibranchium Lutz}

Simulium spinibranchium Lutz, 1910. 2 (2): 248 (pupas), 261, 263-264, fig. 13; Lutz \& Machado, 1915. 7 (2): 46; Pinto, 1931. 60: 712-713, 726-727, 756, 762, fig. 6c; Vargas, 1945. 1: 198; Smart, 1945. 95 (8): 514; Vulcano, 1967. 16: 21; Vulcano et al., 1975. 18 (1-4): 632-634; Vulcano, 1977. p. 293.

Simulium subpallidum Lutz, 1910. 2 (2): 261, 263-264 (parte).

FÊMEA - Coloração geral preta. Comprimento 2,3-2,5 mm (espécimens secos). Comprimento da asa 2,9-3,0 mm.
Cabeça enegrecida. Fronte, clípeo e occiput cinza polinoso. Peças bucais castanho; palpo maxilar castanho escuro. Antena (Fig. 1A) com escapo e pedicelo castanho-laranja, flagelo castanho-preto; pilosidade do flagelo curta e esbranquiçada, do fronte, clípeo e occiput mais longa e dourada. Fronte de largura média; ângulo frontal com 70-79 graus (Fig. 1D). Triângulo fronto ocular tão largo quanto longo (Fig. 1E). Cibário com braços laterais bastante esclerotizados; com a porção mediana menos esclerotizada, inerme, mas podendo apresentar pequenas ondulações centrais (Fig. 1C). Palpo maxilar (Fig 1B) apresentando o segmento apical mais longo que os segmentos III e IV juntos. Vesícula sensorial (Fig. 1G, $\mathrm{H} \mathrm{e} \mathrm{I)} \mathrm{alongada,} \mathrm{o} \mathrm{seu} \mathrm{diâmetro} \mathrm{igual}$ a metade da largura do terceiro segmento do palpo, podendo apresentar variações. Maxilas e mandíbulas com dentes em ambos os lados. Maxila com 28-31 dentes. Mandibula (Fig. 1F) com 7-9 dentes na borda externa e 27-31 na interna. Mesonoto preto com áreas de pruinosidade nacarada; ocorrendo variaçōes na localização das áreas com pruinosidade, dependendo de um maior ângulo de incidência da luz frontal (Fig. O). As mudanças destas áreas pruinosas vão desde $1+1$ submedianas unindo-se na margem anterior do mesonoto, $1+1$ mais largas e laterais, até $1+1$ manchas cuneiformes anteriores, $1+1$ submedianas $e$ $1+1$ mais largas e laterais. Com incidência de luz pela parte posterior observa-se uma inversão na distribuição das áreas pretas $e$ pruinosas. Úmero e pronoto castanhos com pruinosidade cinza-branco. Pronoto e mesonoto com cerdas douradas. Escutelo castanho escuro com cerdas marginais longas, amarelas e

(1) - Instituto Nacional de Pesquisas da Amazônia, Manaus.

(2) - Instituto Oswaldo Cruz (FIOCRUZ), Rio de Janeiro. 
pretas. Posnoto preto com $1+1$ áreas pruinosas nacaradas separadas por uma área mediana longitudinal enegrecida; glabro. Mesepisterno e catepisterno pretos com pruinosidade acinzentada. Sulco mesepisternal bem evidente. Mesepímero castanho escuro com pruinosidade cinza mais condensada que no mesepisterno. Braços do furcasterno com projeções conspícuas (Fig. 1K). Asas com veias de coloração castanho claro. Sc e Seção Basal do $\mathbf{R}$ com setas filiformes. Sc com uma fileira de 16-17 setas. $\mathbf{R}_{1}$ com setas filiformes entremeadas com setas espiniformes. As setas espiniformes de $\mathbf{R}_{1}$ começam na mesma linha de término das setas da Sc (Fig. 1J). Rs simples.

Forma e proporção das patas de acordo com a figura $1 \mathrm{~L}, \mathrm{M}$ e N. Coxa, trocanter, femur e tíbia do primeiro par de coloração castanho-amarelo; porção distal da tíbia enegrecida, diminuindo a área desta coloração na parte posterior; tarsos pretos. Coxa mediana castanho escuro com pruinosidade acinzentada; trocanter, fêmur e tíbia castanho-amarelo, porção distal da tíbia um pouco mais escura. Os primeiros três quartos $(3 / 4)$ do basitarso castanho-amarelo, o quarto (1/4) distal preto; metade basal do segundo segmento tarsal amarelo escuro, metade distal preta; os outros tarsos pretos. Coxa do par posterior castanho єscuro; trocanter e fêmur castanho-amarelo, escurecendo no terço distal do fêmur: metade basal da tíbia amarelo-creme, metade distal preta; basitarso com coloração amarelo-castanho, o quinto distal prefo; tarsos castanho-preto. Calcipala e pedisulco bem desenvolvidos (Fig. 1P). Calcipala tão targa quando comprida, não alcançando o pedisulco. Garras com dente basal (Fig. 1R). Fêmures e tíbias apresentando escamas além das setas (Fig. 1Q). Primeiro tergito abdominal castanho escuro; tergito II apresentando $1+1$ áreas de cor castanho lateralmente e uma área central com reflexos prateados; tergitos III-V castanho escuro com bordo posterior mais claro. Tergitos VI-VII com coloração castanho-preto lustroso. Placas tergais bem esclerotizadas e dispostas de acordo com a figura $1 \mathrm{~S}$. Superfície ventral acinzentada. Oitavo esternito com $1+1$ grupos de 26-30 setas (sendo que destas $6 \cdot 7+6-7$ são pequenas e mais internas). Gonapófises iriangulares, glabras e esclerotizadas na margem interna (Fig. 1U). Cerco e paraprocto como na figura $1 Y$. Forquilha genital com o processo mediano bem esclerotizado (Fig. 1Z). Espermateca oval, com espículas de diferentes tamanhos dispostas em grupos de 1-5 e formando fileiras mais ou menos concêntricas; com o ducto espermático e sua área de inserção membranosos (Fig. 1T).

$\begin{aligned} \text { MACHO - } & \text { Coloração geral preta. Compri- } \\ & \text { mento } 1,9-3,8 \mathrm{~mm} \text { (espécimens } \\ & \text { secos : } 2,3-2,7 \mathrm{~mm} \text {; espécimens } \\ & \text { no álcool : } 1,9-3,8 \mathrm{~mm} \text { ). Com- } \\ & \text { primento da asa } 2,7 \mathrm{~mm} \text {. }\end{aligned}$

Fronte e clípeo cinza-preto. Peças bucais castanho escuro. Forma e proporção do palpo maxilar e da vesícula sensorial conforme a figura 2B e C. Segmento apical do palpo maxilar mais longo do que os segmentos III-IV juntos; vesícula sensorial menor e com menos tubérculos que na fêmea, com o diâmetro igual à metade da largura do terceiro segmento. Antena (Fig. 2D) com coloração igual à da fêmea. Areas pronotais castanho escuro com pruina prateada. Mesonoto com uma larga faixa anterior de pruina nacarada sob luz frontal, com luz incidindo latero-frontal a área pruinosa toma a disposição representada na figura $2 \mathrm{~A}$ : apresentando ântero-dorsal, lateral e posteriormente densa pilosidade de coloração dourada. Escutelo preto com cerdas douradas longas marginalmente. Posnoto preto com pruinosidade prateada uniforme. Pleuras pretas com pruinosidade acinzentada. Asas e pernas com tonalidades de coloração semelhantes às da fêmea. Asa com a Sc inerme e com a Seção Basal do $\mathbf{R}$ com menos setas que na fêmea. Forma e proporções das pernas mostradas na figura $2 E, F$ e G. Calcipala levemente mais larga do que comprida (Fig. $2 \mathrm{H}$ ). Divisão entre os tergitos I e II, tergitos II, VI-VII e pequeno bordo lateral do VIII com $1+1$ manchas pruinosas (prateadas). Tergito IX de coloração acinzentada (cinza-prata). Região ventral cinza escuro. Parâmeros como na figura $2 \mathrm{l}$ e J. Basímero mais largo do que comprido. Distímero aproximadamente tão largo quanto compri- 


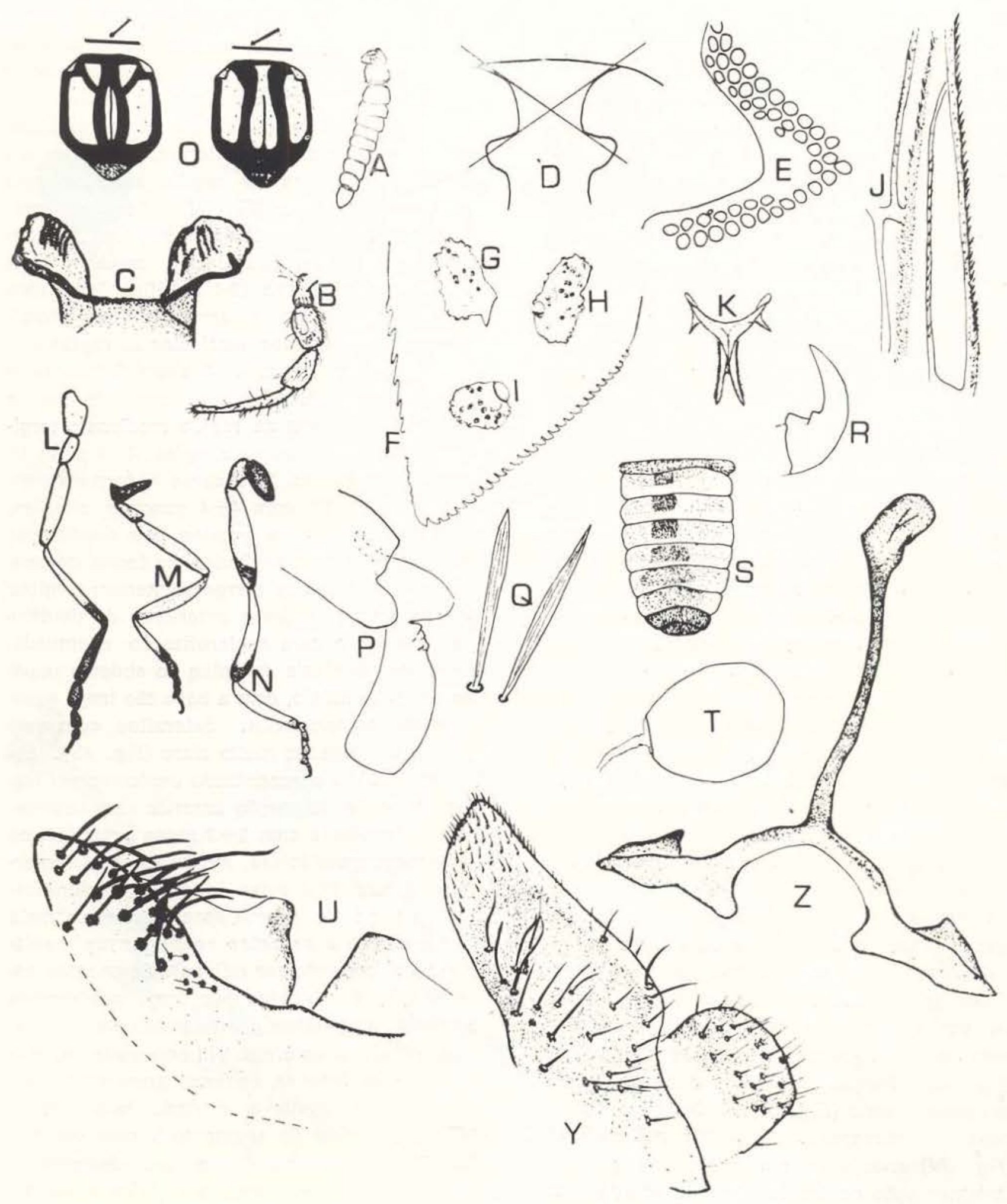

Fig. 1 - Simulium spinibranchium Lutz (fêmea) : A, antena; B, palpo maxilar; C, porção basal do cibário; D, fronte; E, área ocular; F, ápice da mandíbula; G, H e I, órgão sensorial do palpo; J, bordo anterior da asa; K, furcasterno; L, $M \in N$, patas anterior, média e posterior; $\mathbf{O}$, variações na paterna do mesonoto feitas por diferentes ângulos de incidência luminosa; $\mathbf{P}$, calcipala e pedisulco; $\mathbf{Q}$, escamas das patas posteriores; $\mathbf{R}$, unha da pata posterior; $\mathbf{S}$, abdome, vista dorsal; T, espermateca; U, oitavo esternito e gonapófises: Y, paraprocto e cerco; $\mathbf{Z}$, forquilha genital. 
do. Distímero menos comprido que o basímero, sem espinho apical. Placa ventral (Fig. $2 \mathrm{~K}, \mathrm{~L}$ e M) subtriangular; fortemente esclerotizada na base e na parte antero-mediana; com grupos de 2-8 setas espiniformes, pequenas, direcionadas para a parte anterior, sendo mais condensadas na região mediana. Órgão endoparameral (Fig. $2 \mathrm{~N}$ ) com dentes bem conspicuos. Esclerito mediano (Fig. 2O) com porção distal larga e com uma incisão mediana profunda.

\section{PUPA - Comprimento dorsal do casulo: $3,2-4,0 \mathrm{~mm}$; ventral $3,8-4,4 \mathrm{~mm}$. Comprimento dos filamentos branquiais : $2,6-2,7 \mathrm{~mm}$.}

Casulo com a forma de chinelo ("slippershaped"), com a borda anterior reforçada (menos na parte centro-dorsal). Tecido do casulo castanho claro, regular e com trama não perceptível (visível somente com grande aumento óptico). Superfície ventral somente sendo ocupada por tecido na metade posterior (Fig. 3B); as linhas de contacto entre o tecido ventral e as laterais do casulo são mais elevadas que a parte ventral mediana (Fig. 3B e D). Brânquiàs de coloração variando de castanho até acinzentado, compostas de $8 \mathrm{fi}$ lamentos secundários. A base inicialmente é fina, engrossada na formação do tronco comum de onde partem quatro troncos principais : um dorsal que se bifurca, dois medianos (o externo permanece simples enquanto o interno fornece dupla bifurcação dando origem a 3 ramos secundários) e o ventral que se bifurca. Todos os filamentos săo largos na base e afilam para o ápice (Fig. 3E). Superfície da brânquia com pequenos tubérculos irregulares (Fig. 3L). Porção distal dos filamentos com um enrugamento (Fig. 3F). Cabeça e tórax da pupa com numerosas plaquetas polimórficas (Fig. $3 \mathrm{H}$ ) arranjadas em grupos irregulares. Ornamentação do frontoclípeo de acordo com a figura $3 \mathrm{M}$ e $\mathrm{N}$, com $2+2$ tricomas frontais de $2-5$ ramos, normalmente 5 ; com $1+1$ tricomas faciais de 2-4 ramos, normalmente 3 . Quetotaxia do tórax com $5+5$ tricomas centro-dorsais com $7-12$ ramos (Fig. $3 \mathrm{~J}$ ); $3+3$ tricomas laterais (sendo $2+2 \mathrm{com} 6-11$ ramos e $1+1$ mais ventrais, normalmente simples e curtas com a base grossa, mas podendo, raramente, serem bífidas); com $1+1$ tricomas supra-laterais pequenas (2-3 ramos). Tergitos abdominais apresentando uma diminuição de esclerotização no sentido antero-posterior, sendo que em todos, pelo menos na região anterior, esta permanece evidente (Fig. 4R). Tergito ! apresentando-se totalmente castanho, com $3+3$ setas pequenas medianas, tipo espinho; com $2+2$ setas pequenas (2-4 ramificaçōes); com $2+2$ manchas claras arredondadas, lateralmente; com esparsos dentículos na região mediana; tergito II com $4+4$ setas filiformes e $1+1$ áreas antero-laterais com dentículos (também esparsos na região mediana); tergito III com $4+4$ ganchos simples, $4+4$ setas filiformes pequenas, $2+2$ setas filiformes grandes; tergito IV com $4+4$ ganchos simples, $4+4$ setas filiformes grandes, sem dentículos; tergitos VI-IX com espículas em forma de pente em $1+1$ áreas na margem anterior; tergitos VII-VIII com $1+1$ áreas anteriores de dentículos grandes e com esclerotização acentuada. Espinhos terminais do ápice do abdome pupal de tamanho médio, com a base tão larga quanto o seu comprimento. Esternitos com uma coloração castanho muito claro (Fig. 4S). Esternitos III-VIII apresentando espículas em forma de pente na porção anterior dos segmentos. Esternito III com $2+2$ setas espiniformes pequenas, translúcidas, medianamente. Esternito IV com $3+3$ setas filiformes esclerotizadas (o par mais interno apresentando-se mais desenvolvido e as setas sendo curvas medianamente, podendo ser bífidas). Segmentos esternais V-VII divididos por área membranosa estriada longitudinal, medianamente (Py-Daniel, 1979). O esternito VIII com maior ou menor incisão anterior, podendo apresentar área membranosa mediana estriada longitudinal. Placas esternais do segmento $\mathrm{V}$ com esclerotização bastante restrita e bem demarcada; apresentando $2+2$ ganchos (bífidos e/ou trífidos) muito próximos; com $2+2$ setas (simples e/ou bífidas) filiformes, longas e encurvadas, translúcidas, laterais aos ganchos mais externos. Placas esternais VI-VII com $1+1$ ganchos (bífidos e/ou trífidos). Segmentos VI-VII apresentando $1+1$ ganchos (simples) 


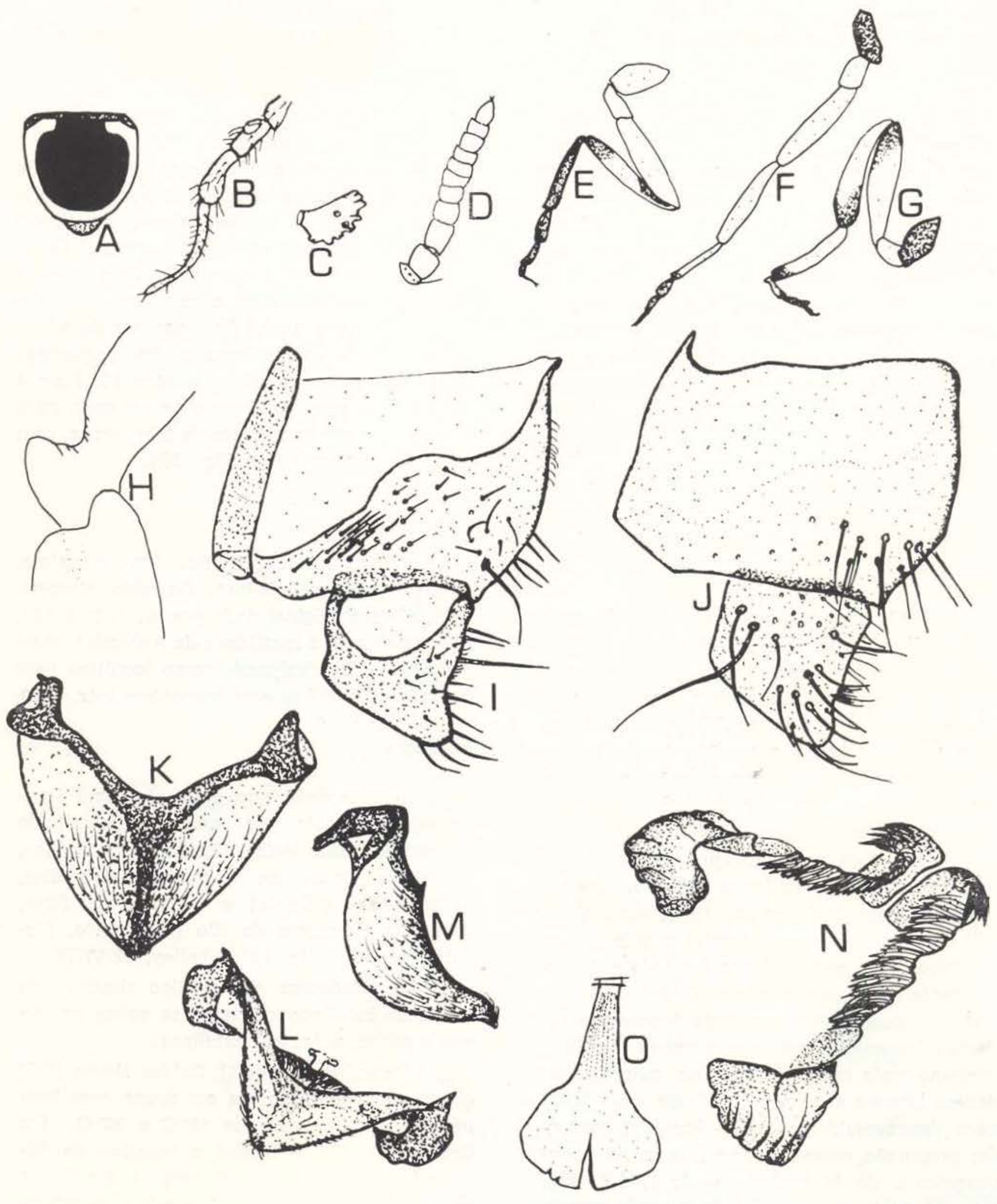

Fig. 2-Simulium spinibranchium Lutz (macho) : A, aspecto geral do mesonoto; B, palpo maxilar; C, órgäo sensorial do palpo; D, antena; E, F e G. patas anterior, média e posterior; H, calcipala e pedisulco; I, e J, diferentes aspectos do parâmetro; K, L e M, diferentes aspectos da placa ventral; N, órgão endoparameral; O, esclerito mediano. 
nas regióes membranosas, laterais as placas esternais (lado externo). Segmento VI com $3+3$ setas filiformes (simples e/ou bífidas) sendo $1+1$ localizadas nas placas esternais e $2+2$ nas regiões membranosas $(1+1$ frontais, bífidas, e $1+1$ postero-laterais, simples, aos ganchos externos). Segmento VII com $3+3$ setas filiformes, pequenas, localizadas na região membranosa $(1+1$ frontais aos ganchos simples da membrana, $1+1$ antero-laterais e $1+1$ postero-laterais as placas esternais). Esternito VIII com $2+2$ setas filiformes localizadas nas membranas $(1+1$ laterais, simples, e $1+1$ posteriores, simples e/ou bífidas, a placa esternal). Laterotergitos dos segmentos V-VII incluindo os espiráculos e bem evidentes.

\section{LARVA - Coloração de cinza claro a ver- de claro. Comprimento $6,0-7,5 \mathrm{~mm}$. Máxima largura da capsuia cefá- lica $0,68 \mathrm{~mm}(0,64-0,68 \mathrm{~mm})$.}

Cutícula com pequenas setas espiniformes e filiformes (translúcidas). Apótoma cefálico (Fig. 5C) castanho claro com pigmentação mediana e posterior mais escura. Largura máxima do apótoma: $0,53 \mathrm{~mm}$. Porção posterior da capsula cefálica e escleritos cervicais conforme figura 5D. Antena com forma e pigmentação de acordo com a figura $5 \mathrm{E}$. Proporção entre os segmentos antenais $\mathrm{I}-\mathrm{III}=1: 1-1,1$ : 1,75. Antena de tamanho igual ou levemente menor que a haste do leque cefálico. Leques cefálicos com 37-39 raios. Hipostômio (Fig. 5G) com 6-7+6-7 setas laterais; com 2-5 setas no disco; mais esclerotizado fronto-lateralmente; dente mediano proeminente, igual ou maior que os dentes latero-apicais (corner-teeth); dentes intermediários bem menores, sendo o mediano mais curto do que os outros dois; dentes laterais e serrilhas (5-7 de cada lado) bem desenvolvidos. Fenda Posgular profunda; proporção entre o comprimento da ponte posgular e do hipostômio $=1$ : 1,7-1,8 (Fig. $5 \mathrm{H})$. Histoblasto branquial da pupa de acordo com a figura 51 . Dentição da mandíbula (Fig. 5J) apresentando três dentes subapicais, conspicuamente decrescendo em tamanho no sentido do primeiro para o terceiro; duas fileiras de dentes internos (com 10 dentes na inferior e 6-7 dentes na superior); com dois dentes marginais, surgindo mais raramente um terceiro dente muito pequeno entre estes dois (Fig. $5 \mathrm{~K})$. Com 18-24 dentículos na parte latero-posterior externa da mandíbula (Fig. 5L). Palpo maxilar de acordo com a figura $5 \mathrm{M}$. Esclerito lateral do pseudópodo (Fig. $5 \mathrm{~N}$ ) pouco esclerotizado, com setas de tamanho desigual, em uma única fileira (grupos de $1-5$ setas). Esclerito anal conforme a figura 50 . Com $4-5+4-5$ setas entre o disco anal e os braços posteriores do esclerito anal. Com um par de tubérculos ventrais posteriores muito pequenos. Disco anal com aproximadamente 80 fileiras de ganchos, com 12-15 ganchos em cada uma. Brânquias anais compostas de três ramos, com 11-13 lóbulos cada um (Fig. 5P).

\section{LECTÓTIPO}

A lâmina n: 12.337 (Bd. 118), pupa/macho, da coleção Lutz-Inst. Oswaldo Cruz-RJ, cujo número original dado por $\mathrm{A}$. Lutz é 181 , etiquetada com a localidade de Anhemby (atual Anhembi), fica designada como lectótipo para a espécie Simulium spinibranchium Lutz, 1910.

\section{BIOLOGIA}

É uma espécie que aparentemente apresenta preferência por substrato constituído de pedras (Saia Velha, Goiás, col. Shelley, $30 / 1 X / 74$; Cach. de Cristalina, Cristalina, Goiás, cols. Py-Daniel e Faustino da Silva, 29/III/76; Barragem do Rio Descoberto, Distrito Federal/Goiás, col. Shelley, 02/VI/76.

Seus criadouros são do tipo aberto, com luz solar incidindo diretamente sobre as larvas e pupas, e águas cristalinas.

Vulcano, et al., (1975), Caldas Novas (GO) observaram esta espécie em águas com temperaturas que variam de $18^{\circ} \mathrm{C}$ a $20^{\circ} \mathrm{C}$. Em Cristalina (GO), Py-Daniel e Faustino da Silva coletaram pupas desta espécie em águas com temperatura de $24,5^{\circ} \mathrm{C}$, sendo aí constatada uma velocidade, superficial, das águas de $80 \mathrm{~cm} / \mathrm{seg}$.

O Simulium spinibranchium convive com o S. pruinosum na Barragem do rio Descoberto 

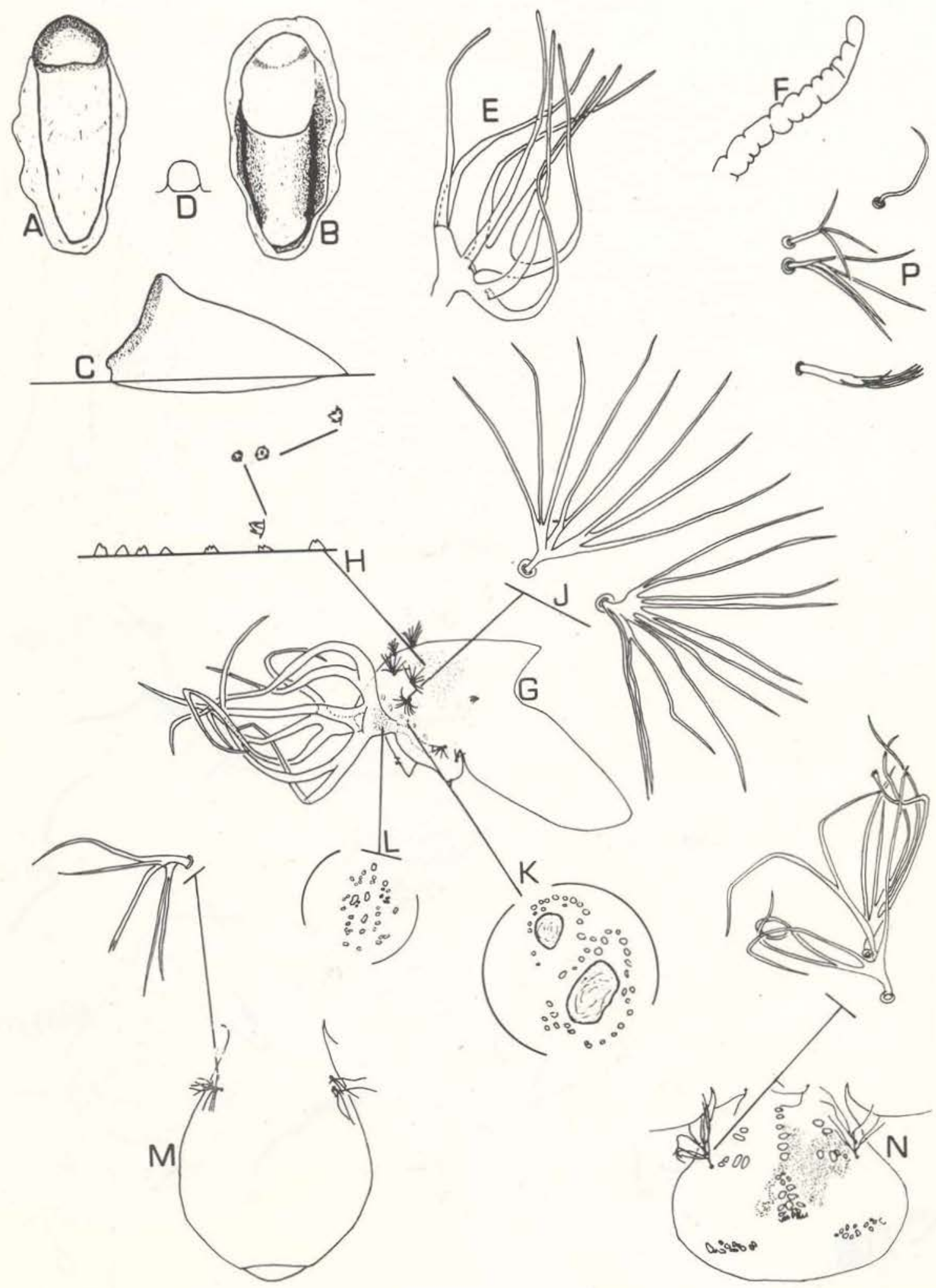

Fig. 3-Simulium spinibranchium Lutz (pupa) : A, B e C, aspecto geral do casulo, dorsal, ventral e lateral; D, esquema de um corte transversal do casulo: E, branquia; F, porção distal de um filamento branquial; G, aspecto geral do tórax, pterateca e filamentos branquiais; H, plaquetas polimórficas do tórax; J, tricomas centro-dorsais; L, tubérculos da branquia; K, plaquetas do tóraxe, posteriores a inserção branquial; M, frontoclipeo da pupa macho; N, frontoclipeo da pupa fêmea; P, tricomas anormais do tórax. 


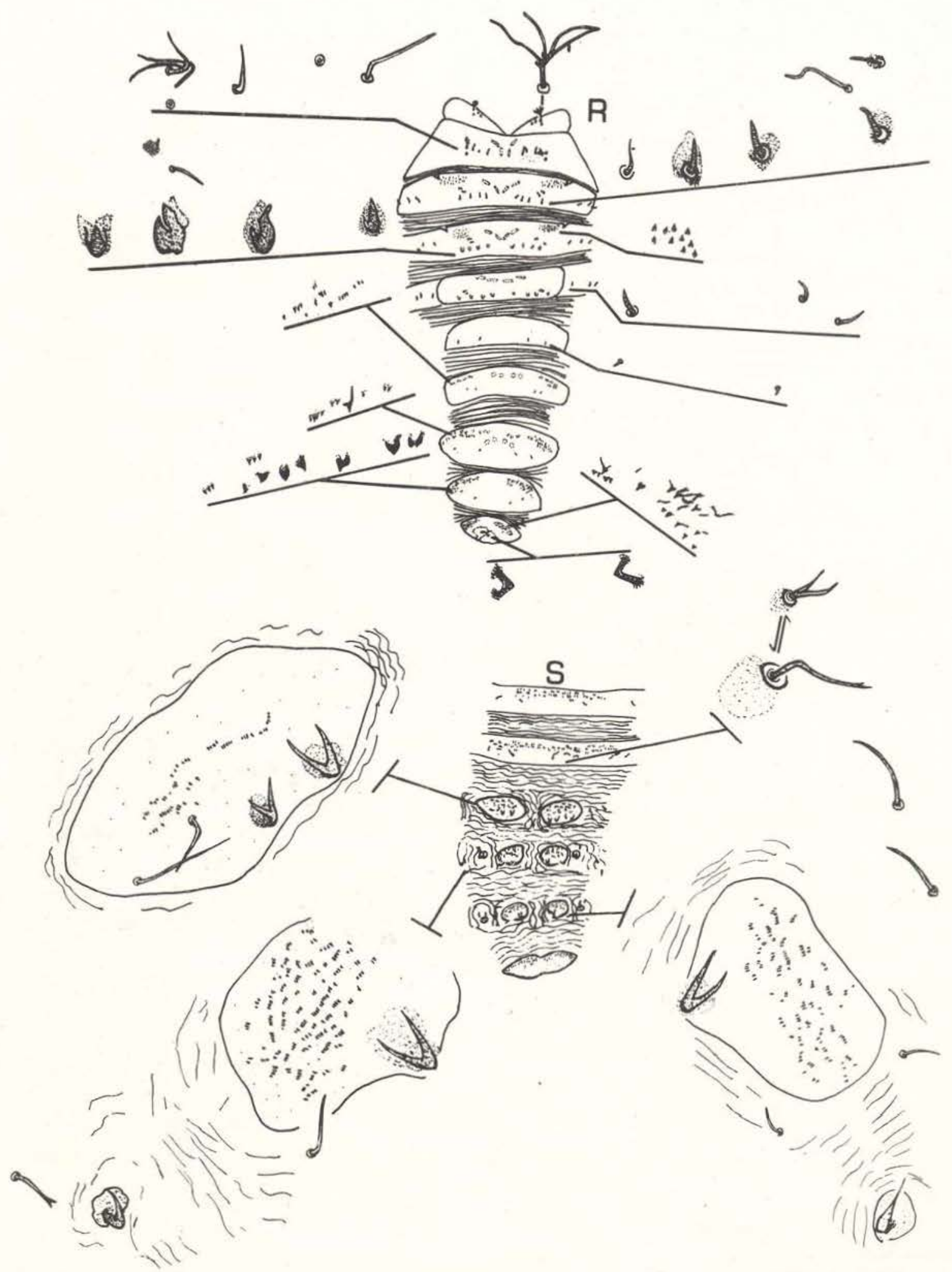

Fig. 4 - Simulium spinibranchium Lutz (pupa) : R, aspecto geral dos tergitos abdominais; S, aspecto geral dos esternitos abdominais. 


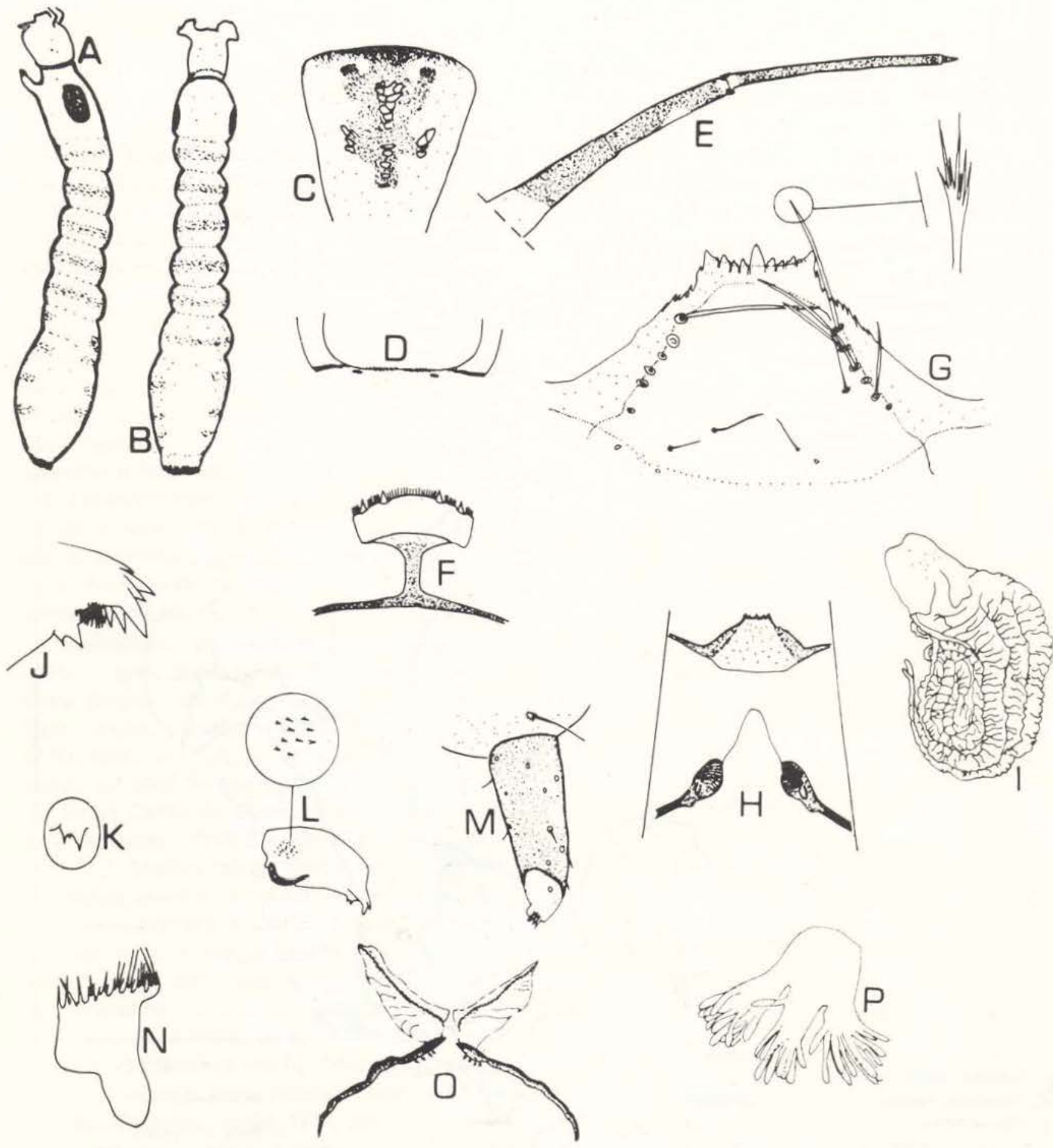

Fig. 5-Simulium spinibranchium Lutz (larva) : A e B, aspecto geral da larva; C, apótoma cefálico; D, escleritos cefálicos com a porção posterior da capsula cefálica; E, antena; F, esclerito labral; G, hipostômio; H, aspecto ventral da capsuìa cefálica; I, histoblasto branquial da pupa; J, porção apical da mandibula; K, variação dos dentes marginais; L, mandibula e dentículos latero-posteriores; $\mathrm{M}$, palpo maxilar; $\mathrm{N}$, esclerito lateral do pseudópodo; $\mathrm{O}$, esclerito anal; P, branquias anais. 
(GO), col. Shelley, 1976 e no córrego Colombo, canal de São Simão (GO), cols. Vulcano et al. (1975); com o S. subpallidum no córrego Colombo, c. de São Simão e em Caldas Novas, Balneário Pousada do rio Quente, (GO), cols. Vulcano et al. (1975).

Apresenta uma distribuição geográfica não muito grande, pois até o presente, somente foi detectado no nordeste da Bacia Paraná-Paraguai-Uruguai (Bacia do Prata), sul da Bacia do São Francisco e sul da Bacia do Leste, nas quais os criadouros estão localizados a altitudes que variam de $350-400 \mathrm{~m}$ até 1.000 $1.200 \mathrm{~m}$.

\section{MATERIAL EXAMINADO}

Uma série de lâminas (síntipos) da coleção Lutz-Inst. Oswaldo Cruz, RJ; do n. 12.326 (Bd. 118) ao n. ${ }^{\circ} 12.334$ (Bd. 118) - Anhemby (Tietê), atualmente Anhembi:SP; do n. 12.336 (Bd. 118) ao n. 12.337 (Bd. 118) - Anhemby;

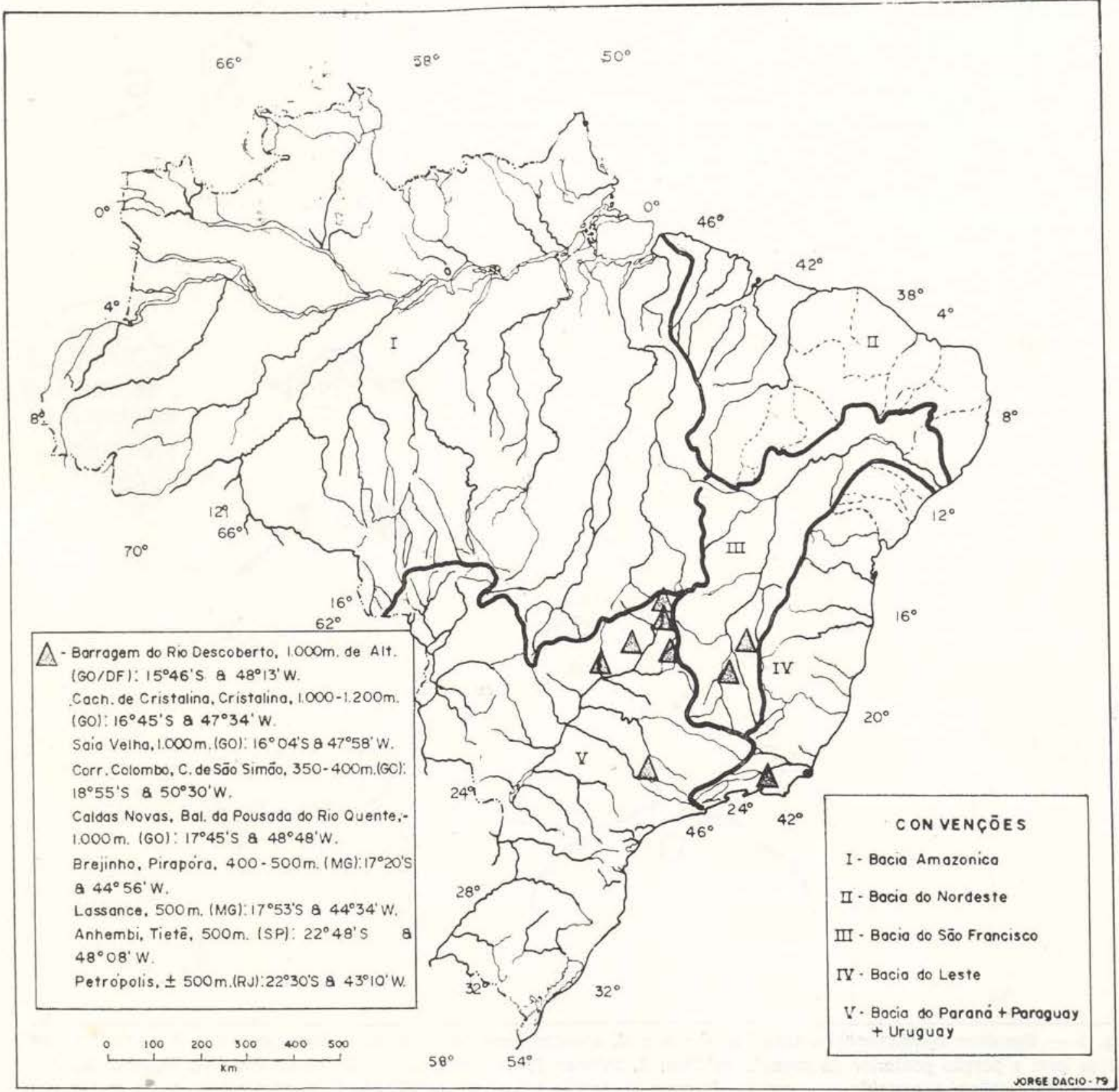

Fig. 6 - Distribuição geográfica de Simulium spinibranchium Lutz, 1910 
n. ${ }^{\circ} 12.338$ (Bd. 118) - Anhemby (?); n. 12.355 (Bd. 118) - Anhemby; n. ${ }^{\circ} 12.361$ (Bd. 120) Anhemby; n. 12.362 (Bd. 120) - Lassance: $M G$; do $n .{ }^{\circ} 12.364$ (Bd. 120) ao n. 12.366 (Bd. 120) - Anhemby.

O material destas lâminas está restrito a pupas com imagos (machos e fêmeas) em péssimo estado de conservação.

Uma série de exemplares (montados em alfinetes) na coleção Lutz-Inst. Oswaldo Cruz, RJ, com a denominação de $S$. spinibranchium : n. 12.643 - Paranapanema, 15 a $17 / \mathrm{XI} / 1910$, 1 macho e 6 fêmeas (não são $S$. spinibranchium); n. 12.644 - Ouro Fino, X/1911, 2 fêmeas (não são S. spinibranchium); n. ${ }^{\circ} 12.645$ - Juiz de Fora, Faz. Chagas, 2 fêmeas (não são S. spinibranchium); n. 12.646 - Sem procedência e nem data de coleta, 1 fêmea (não é S. spinibranchium); n. ${ }^{\circ} 12.647$ - Sem procedência e nem data de coleta, 3 fêmeas (não são S. spinibranchium); n.0 12.648 - Juiz de Fora, Água Lima, X/1909, 1 fêmea (não é $S$. spinibranchium).

Exemplares pertencentes à coleçăo do INPA - Inst. Nacional de Pesquisas da Amazônia (Depto. de Parasitologia): $n{ }^{\circ} 5501-$ Saia Velha, Goiás $\left(16^{\circ} 04^{\prime} S\right.$ \& $\left.47^{\circ} 58^{\prime} \mathrm{W}\right)$, 30/IX/1974, col. A.J. Shelley, uma exúvia pupal; $n .^{\circ} 5502$ - Barragem do rio Descoberto, divisa Oeste do Distrito Federal com o Estado de Goiás (1546'S \& 48 13'W), 08/VI/1976, col. A.J. Shelley, várias pupas, larvas, fêmeas e machos criados; $n .^{\circ} 5503$ - Petrópolis, Rio de Janeiro $\left(22^{\circ} 30^{\prime}\right.$ 'S \& $\left.43^{\circ} 10^{\prime} \mathrm{W}\right), 12 / \mathrm{V} / 1979$, col. S. Coscarón, 1 macho criado e a respectiva exúvia pupal com casulo; n.5504 - Cach. de Cristalina, Cristalina, Goiás (1645'S \& $47^{\circ} 37^{\prime}$ W), 29/III/1976, cols. V. Py-Daniel e B. Faustino da Silva, 1 macho criado e a respectiva exúvia pupal com casulo; Cach. de Cristalina, Cristalina, Goiás, 1976, col. A.J. Shelley, 1 macho criado e a respectiva exúvia pupal com casulo, 4 pupas.

\section{AGRADECIMENTO "POST MORTIS"}

O primeiro autor agradece a Frei Walter Wolfgang Kempf pela orientação e críticas apresentadas a este trabalho (iniciado em 1975).

\section{SUMMARY}

Adults and larva of Simulium spinibranchium Lutz. 1910 are described for the first time and the pupa is redescribed. A lectotype is estabilished for the species. The Geographical Distribuition and some Biologic data are presented.

\section{BIBLIOGRAFIA}

Lutz, A.

1910 - Segunda contribuição para o conhecimen. to das espécies brazileiras do gênero "Si. mulium". Mem. Inst. Oswaldo Cr:1z, 2 (2): 213-267, pls. 18-21.

Lutz, A. \& MAChudo, A.

1915 - Viagem pelo São Francisco e por alguns dos seus afluentes entre Pirapóra e Joazeiro. Mem. Inst. Oswaldo Cruz, 7 (1-2) 5-49, pls. $1-18$.

PINTO, C.

1931 - Simuliidae da América Central e do Sul. In: 7: Reun. Soc. Argent. Patol. Reg. Norte, 60: $661-763$.

PY-DanIEL, $\mathrm{V}$.

1979 - Algumas consideraçōes sobre Simuliidae (Diptera, Nematocera). Acta Amazonica, 9 (4): $783-786$.

SMART, J.

1945 - The classification of the Simuliidae (Diptera). Trans. R. ent. Soc. London, 95 (8) 463-532.

VARGAS, L.

1945 - Simulidos del Nuevo Mundo. Monogr. Inst . Sal. y Enf. Trop., México, 1: VI + 241pp., 10 pls.

Vulcano, M.A.

1967 - Family Simuliidae. In A Cataloque of the Diptera of the Americas South of the United States. Dept. Zool. Secr. Agr., São Paulo (16): $1-44$.

1977 - Family Simuliidae. In: Biota Acuática de Sudamérica Austral. I parte, pp. 1*342, San Diego State University, Califórnia, USA.

Vulcano, M.A.; Valle, C.M.C. \& Peretra, F.S.

1975 - Notas à Margem de uma Excursão Entomológica a Minas Gerais, Goiás e Brasília. Studia Ent , 18, (1-4): 631-634.

(Aceito para publicação em $16 / 08 / 79$ ) 